\title{
Aspergiloma pulmonar bilateral
}

\section{Bilateral lung aspergilloma}

\section{Rachid Bouchentouf '}

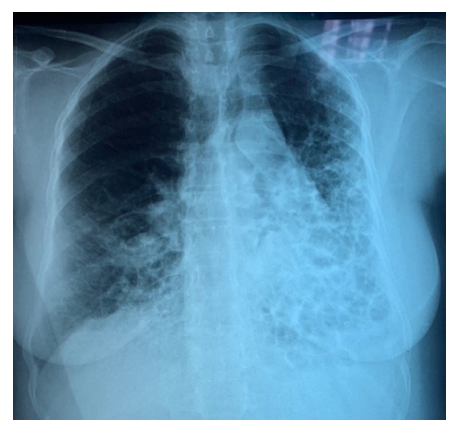

Figura I. Radiografía torácica mostrando una lesión cavitada pulmonar derecha y bronquiectasias quísticas en el hemitórax izquierdo
Bouchentouf R.Aspergiloma pulmonar bilateral. 202I;34(2): 87.

https://doi.org/10.36393/spmi.v34i2.604

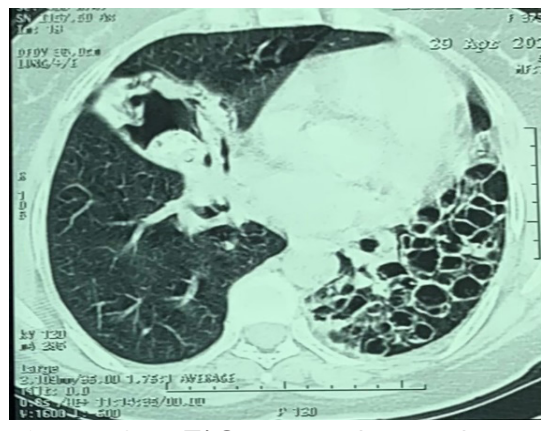

Figura 2A: TAC: aspergiloma pulmonar complicando secuela de tuberculosis en el pulmón derecho.

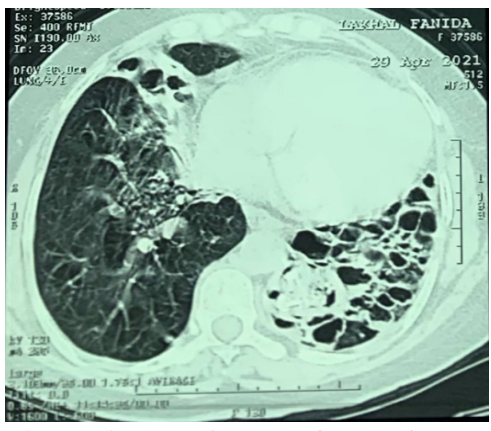

Figura 2B: TAC: aspergiloma pulmonar complicando bronquiectasias en el pulmón izquierdo.
Mujer de 45 años de edad, no fumadora, con antecedente de bronquiectasias desde su infancia; tuberculosis pulmonar tratada en 2015. Acudió al servicio con un cuadro de 15 días de evolución, tos con expectoración mucopurulenta y episodios de hemoptisis leve, disnea, fiebre y malestar general. Examen físico: paciente disneica, PA 120/85mm $\mathrm{Hg}$, frecuencia respiratoria 24 ciclos $/ \mathrm{min}$, Sat $\mathrm{O}_{2}$ 93\% y con hipocratismo digital. En la auscultación: disminución del murmullo vesicular del hemitórax izquierdo y presencia de roncus. Exámenes auxiliares: hemograma con 8590 leucocitos por $\mathrm{mm}^{3}$ (59\% neutrófilos, $31 \%$ linfocitos), $\mathrm{Hb}$ $10,5 \mathrm{~g} / \mathrm{dl}$, proteína $\mathrm{C}$ reactiva $43 \mathrm{mg} / \mathrm{l}$. Radiografía de tórax: lesión cavitada pulmonar derecha y bronquiectasias a nivel del lóbulo inferior izquierdo (Figura 1). La baciloscopia fue negativa, se inició un tratamiento de amoxicilinaácido clavulánico 3g/día y ciprofloxacina $200 \mathrm{mg} \mathrm{2x/día.}$ Fibrobroncoscopía: aspecto inflamatorio difuso bilateral predominante en la pirámide basal izquierda. Se realizó una aspiración bronquial con estudio directo y cultivo para hongos que resultó positivo para Aspergillus fumigatus. La tomografía computarizada torácica: imagen compatible con aspergiloma en ambos pulmones. (Figuras $2 \mathrm{a}$ y $2 \mathrm{~b}$ ). Pruebas de función respiratoria: patrón de tipo restrictivo moderado.

\footnotetext{
Servicio de Neumología; Hospital Militar Avicena, Marrakech, Marruecos ORCID: https://orcid.org/0000-0003-4839-390X
}

En espera para completar la valoración preoperatoria y optar por un tratamiento quirúrgico, la paciente fue tratada con itraconazol 400mg día oral.

El aspergiloma es la forma más común de la aspergilosis pleuropulmonar. Suele ser unilateral y de predominio en el lóbulo superior; y, generalmente, se desarrolla en una cavidad pulmonar preexistente secuela de tuberculosis y en bronquiectasias. Puede ser tolerado por muchos años sin causar síntomas, de los cuales el más frecuente suele ser la hemoptisis de intensidad variable. El diagnóstico se basa en los hallazgos clínicos, imágeens y confirmación por histopatología. Los antifúngicos no han demostrado ser eficaces por lo que la cirugía, a pesar de una elevada morbilidad, continúa siendo el tratamiento de elección.

\section{REFERENCIAS BIBLIOGRÁFICAS}

I. Torales M, Martínez F, Bagattini JC. Aspergiloma pulmonar bilateral. Arch Med Interna. 2010; XXXII (2-3):53-56.

2. Martínez J, Márquez M, Sola O, Arés J, Grarau J. Tratamiento del aspergiloma pulmonar: Revisión clínica. Enferm infecc Microbiol Clin. 2000; 18:413-5.

\section{CORRESPONDENCIA:}

Rachid Bouchentouf,

bouchentouf_rachid@yahoo.fr

Fecha de recepción: 17-05-2021.

Fecha de aceptación: 07-06-2021.

Financiamiento: por el autor.

Conflicto de interés: ninguno, según el autor. 